\title{
Genetic Markers on Chromosome 19p and Prenatal Diagnosis of HLA Class II-Deficient Combined Immunodeficiency
}

\author{
HANS-HEINRICH FÖRSTER, RALPH WÄSCH, TOBIAS KRETSCHMAR, DIETMAR MISCHKE, \\ BARBARA UCHAŃSKA-ZIEGLER, ANDREAS ZIEGLER, MARKUS SCHMITT, AND \\ HANS-ULRICH WAHN \\ Institut für Experimentelle Onkologie und Transplantationsmedizin [H.-H.F., R.W., T.K., D.M., B.U.-Z., \\ A.Z.] and Kinderklinik und -Poliklinik [M.S., H.-U.W.], Universitätsklinikum Rudolf Virchow, \\ Freie Universität Berlin, D-14050 Berlin
}

\begin{abstract}
ABS
HLA class II-deficient combined immunodeficiency (CID) is
an inherited disease characterized by a total lack of HLA class II an inherited disease characterized by a total lack of HLA class II In the family investigated the disease phenotype occurs parallel to an abnormal structural feature of the CD23 antigen. We sequenced parts of the FCER2 gene coding for CD23 and found a restriction fragment length polymorphism (RFLP) that cosegregates with the disease. Analysis of recombinant haplotypes by microsatellites mapping to the chromosomal region 19p13.3 suggests that the disease locus maps between FCER2 and the microsatellite marker D19S424, probably close to D19S216 and
\end{abstract}

In class II-deficient CID the HLA class II genes are not transcribed, and expression of HLA class I antigens on the cell surface is also reduced (1). The clinical consequences are hypo- or agammaglobulinemia and impaired cell-mediated immunity resulting in repeated, severe infections and intractable diarrhea with dystrophy caused by malabsorption (2). Currently, the only curative therapy is bone marrow transplantation, whereas under symptomatical therapy most patients die between the age of 6 mo and 5 y (3).

The disease is inherited as an autosomal recessive trait with a high degree of consanguinity. Although none of the patients expresses HLA class II mRNA, the genetic defect does not segregate with the HLA complex. Hence, these observations suggest a defect in class II regulatory genes which are unlinked to the major histocompatibility complex (4) encoding, for example, class II promoter-binding proteins (5).

HLA class II antigens have a restricted tissue distribution, their expression is under tight transcriptional control and can be induced by various stimuli, e.g. by interferon- $\gamma$. Corre-

Received for rapid publication June 2, 1995; accepted July 17, 1995.

Correspondence: Hans-Ulrich Wahn, Kinderklinik und -Poliklinik, Universitätsklinikum Rudolf Virchow, Freie Universität Berlin, Heubnerweg 6, D-14050 Berlin, Germany.
D19S177. These data may offer the possibility of a rapid and early prenatal diagnosis of a subgroup of patients with HLA class II-deficient CID. (Pediatr Res 38: 812-816, 1995)
Abbreviations
CID, combined immunodeficiency
PCR, polymerase chain reaction
SSCP, single-strand conformation polymorphism
RFLP, restriction fragment length polymorphisms
FACS, fluorescence-activated cell sorter

spondingly, several cis-acting elements have been identified in the promoter regions of HLA class II genes (6).

Fusion experiments among several cell lines from patients as well as in vitro generated mutant cell lines displaying the HLA class II-deficient phenotype have established four different complementation groups (7). In three of these complementation groups all class II promoter elements seem to be unoccupied in vivo although the currently known factors that recognize HLA class II promoter elements can be detected in vitro (8).

The fourth complementation group exhibits normal binding of promoter elements by their respective proteins. A transacting factor termed CIITA has been isolated recently. It has been shown that HLA class II expression can be restored in cells belonging to this group (9) upon transfection with CIITA cDNA, but not in a cell line established from a deceased class II-CID patient of the family studied.

EBV-transformed cell lines established from the affected children of this family, but not from the healthy family members, show an abnormality in their CD23 antigen. Although it reacts normally with other antibodies directed against $\mathrm{CD} 23$, it is not recognized by the MAb TÜ1 (10). If this variation reflects a genetic polymorphism in the CD23 gene (FCER2), it would suggest linkage between the class II regulatory gene 
defect and FCER2, which has been mapped to chromosome 19 p13.3 (11). To test this hypothesis, we have analyzed the CD23 gene and several highly polymorphic markers mapping to the $19 \mathrm{p} 13.3$ region in the disease family.

\section{METHODS}

General. HLA class II antigens were determined by fluorescence-activated cell cytometry. DNA and RNA were isolated by standard procedures (12) from cells of both parents, three healthy children, two of the affected children, and a chorionic villi sample and fetal blood of an umbilical cord puncture from the pregnant mother.

cDNA was synthesized and amplified using the GENE Amp RNA PCR Kit (Perkin-Elmer, Norwalk, CT) according to the manufacturer's protocol. PCR products were sequenced directly with the Cycle Sequencing Kit (Perkin-Elmer). SSCP analysis was done as described previously (13).

Analysis of the FCER2 locus. Oligonucleotide primers used are listed in Table 1. The determined RFLP were tested for all family members by PCR amplification using the primers CD23-1 up and CD23-1 down for BstNI or CD23-3 up and CD23-4 down for HpalI RFLP. Amplification reactions contained $100 \mathrm{ng}$ of genomic DNA and $200 \mathrm{nM}$ of each oligonucleotide primer in a $50-\mu \mathrm{L}$ reaction volume. The reactions were run for 35 cycles, 1 min each at 94,60 , and $72^{\circ} \mathrm{C}$. PCR products were digested overnight with $B s t \mathrm{NI}$ or $\mathrm{HpaII}$ restriction endonuclease, separated on a $15 \%$ polyacrylamide gel $(160 \times 140 \times 0.75 \mathrm{~mm})$, and detected by silver staining.

Microsatellite analysis. Genomic DNA was amplified with the highly polymorphic microsatellite markers D19S247 (14), D19S209 (15), D19S424 (16) D19S216 (15), D19S406 (16), D19S413 (16), D19S221 (15), D19S226 (15), D19S177 (17), UT486 (18), and LIPE (19) under conditions given in the respective references. Products were analyzed by native or denaturing polyacrylamide gel electrophoresis or by SSCP.

\section{RESULTS}

In the consanguineous family studied (parents are cousins), two girls and one boy were affected by MHC class II deficiency. Three out of six siblings are healthy (two girls and one boy).

The affected son was born healthy and of normal weight without any problems. After the neonatal period he developed

Table 1. Oligonucleotide primers used for $P C R, R N A-P C R$, and direct sequencing of FCER2

\begin{tabular}{llc}
\hline \multicolumn{1}{c}{ Denotation } & \multicolumn{1}{c}{ Sequence $\left(5^{\prime} \rightarrow 3^{\prime}\right)$} & $\begin{array}{c}\text { Product } \\
\text { length }(\mathrm{bp})\end{array}$ \\
\hline CD23-1 up & CGGGAGAATCCAAGCAGGACCG & 266 \\
CD23-1 down & TGCGCCATCTGGTCACCG & \\
CD23-2 up & GGAACGTCTCTCAAGTTCCAAGAAC & 449 \\
CD23-2 down & GGTCAGGAAGTCCTGCTCCTCC & \\
CD23-3 up & TCGGCAAGGGCACCAAGC & 468 \\
CD23-3 down & GGTCTTGCTCTGGGCCTGGCTG & \\
CD23-4 down & CCACATGGCTCCCATCCACC & \\
\hline
\end{tabular}

protracted diarrhea, recurrent respiratory infections, and severe malabsorption leading to failure to thrive. Agammaglobulinemia developed after 3 mo, and IgG was substituted. Parenteral nutrition was necessary. B cell as well as $\mathrm{T}$ cell count was inconspicious. Severe CID classified as MHC class II deficiency was diagnosed by a immunorosette-forming technique and by immunohistochemical staining with anti-HLA-DR $\mathrm{mAB}$. He died at an age of $20 \mathrm{mo}$, after a sudden attack with dyspnea, cyanosis, and bradycardia, despite immediate cardiopulmonary resuscitation. Septic shock and pulmonary embolism were mainly discussed as the differential diagnosis.

In the first affected girl the same clinical problems occurred. Agammaglobulinemia and immunologic findings led, as in the affected brother, to the diagnosis of MHC class II deficiency. Bone marrow transplantation was planned and performed. She died during a severe sepsis $1 \mathrm{wk}$ after haploidentical bone marrow transplantation in the 5 th y of life.

MHC class II deficiency could be diagnosed by FACScan analysis in the second affected girl immediately after birth, before clinical symptoms occurred. The immunologic findings showed a complete lack of HLA class II molecule expression on B lymphocytes and activated $\mathrm{T}$ lymphocytes and the absence of serum immunoglobulins, as well as no in vitro responses to specific antigens. Haploidentical bone marrow transplantation was performed at the age of $5 \mathrm{mo}$. The father served as donor. After transplantation a chimeric pattern of MHC class II-negative and MHC class II-positive cells was present in the peripheral blood of the child. Delayed hypersensitivity skin tests became positive for tetanus, and diphtheria antigen as well as tetanus antigen-induced lymphocyte proliferation showed normal values. Ig production remained negative and IgG was given further on. Despite the improved cellular immunity gastrointestinal symptoms (diarrhea, malabsorption) persisted. At last the girl died during a severe septic infection with different Gram-negative rods and Candida albicans.

We isolated DNA and RNA from cells of both parents, three healthy children (C1-C3), two of the affected children (C4 and C5), and a chorionic villi sample and fetal blood of an umbilical cord puncture from the pregnant mother (C6) (Fig. 1a). Cells of C6 showed normal expression of HLA class II antigens.

To analyze the nature of the aberrant TÜ1 epitope on CD23, we amplified parts of the CD23 cDNA by PCR using primers that were deduced from the published sequence $(20,21)$. After restriction enzyme digestion to yield fragments smaller than $300 \mathrm{bp}$, the products were examined by SSCP analysis. Fragments showing heterozygosity in the parents were further examined by direct sequencing. We found two transitions, the first being located in exon 4 causing a $\mathrm{Arg}^{62} \rightarrow$ Trp exchange and creating a new Bst $\mathrm{NI}$ restriction site. The second point mutation, located in exon 9, causes an amino acid exchange $\operatorname{Arg}^{188} \rightarrow$ GIn (Fig. 1c) and, concurrently, the destruction of a HpaII restriction site. We analyzed both RFLPs for cosegregation with the disease phenotype and found that the HpaII RFLP cosegregates with the disease in the reported family (Fig. $1 b$ ), with the exception of child C6. In contrast, the Bst NI RFLP segregates independently of the disease. Moreover, it 

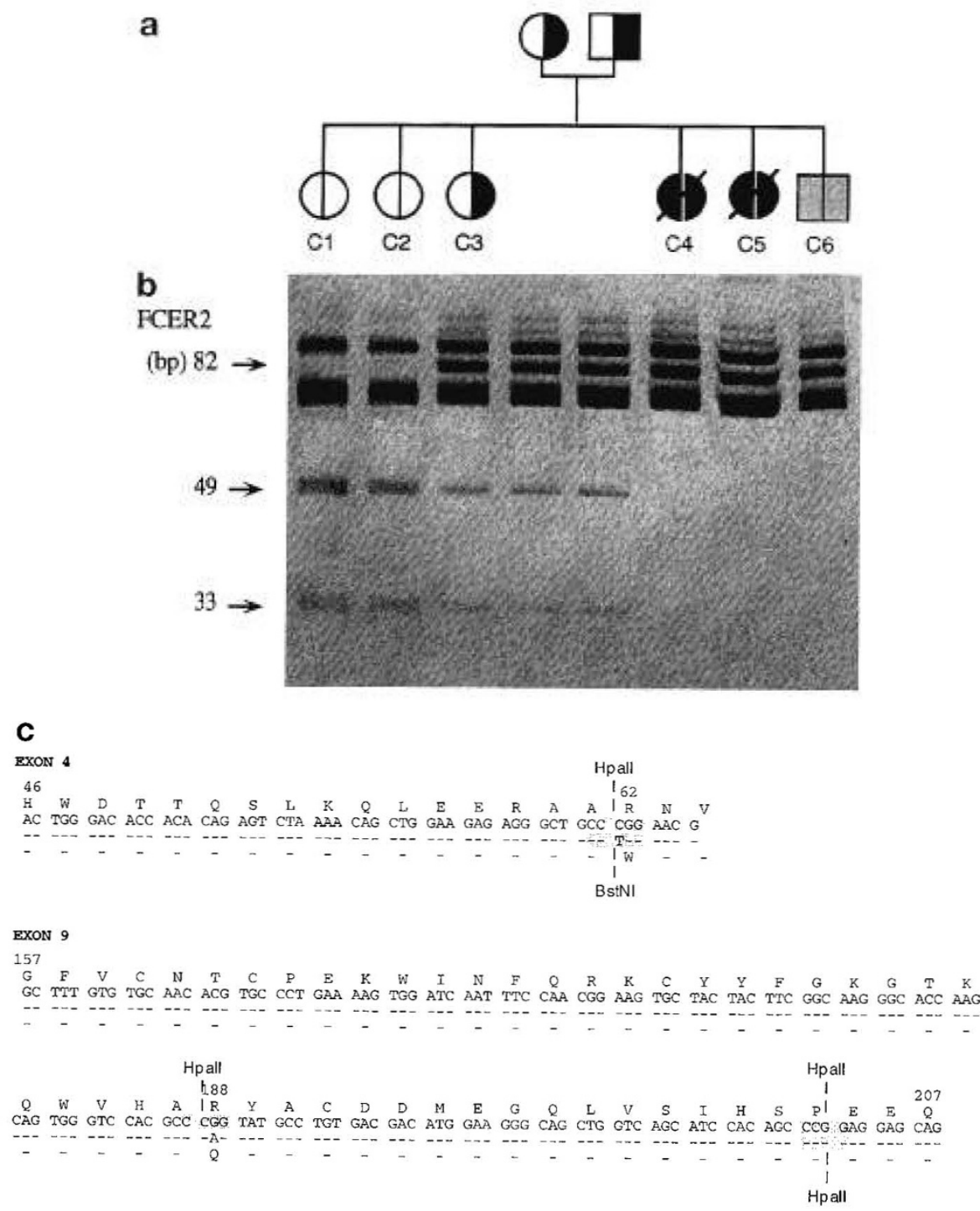

Figure 1. Segregation patterns of the FCER2 gene in the family studied. Filled symbols represent the disease associated FCER2 alleles. The two recombinant chromosome 19 haplotypes of C6 are shown in gray. The pedigree has been aligned to the lanes of the gels. (a) Pedigree of the family members, with their presumed genetic constellation for the disease locus. An additional deceased child was also homozygous for the CD23 mutation (Arg ${ }^{188} \rightarrow$ Gln) as detected by TÜ1 (10). (b) RFLP analysis of a PCR fragment spanning exon 9 and 10 of the CD23 gene. Fragments were digested with Hpall, separated on a $15 \%$ polyacrylamide gel and detected by silver staining. The normal sequence yields two fragments, 33 and 49 bp long; in the aberrant sequence (Arg ${ }^{188} \rightarrow$ Gin) one HpaII site is missing yielding an 82-bp allele. (c) Transitions in the FCER2 gene in the investigated family. The upper rows show the normal allele, the lower rows show diverging residues. Numbering denotes amino acid positions. Restriction enzyme sites tested are shaded.

also appeared in the completely unrelated EBV-transformed cell line H2LCL.

We then analyzed several highly polymorphic microsatellite markers mapping to the 19p13.3 region, as shown in Fig $2 a$. This map is based on the marker distances given in Gyapay et al. (16), therefore the locations of markers D19S177, D19S247, and UT487 are given as ranges. Of the 11 primer pairs used, the marker LIPE (19) was unsuitable due to homozygosity exhibited by both parents. The segregation patterns of the other markers fall into four classes. An example of each of these is given in Fig $2 a$. Assuming single crossing overs as the most likely events, one crossing over between markers D19S424 and D19S216 in the mother, and one between D19S177 and UT486 in the father can be postulated to create the two haplotypes observed in C6. Most likely, another crossing over between D19S413 and D19S221 has occurred in one of the father's ancestors. From these results an order for the markers analyzed can be deduced (Fig. $2 b$ ), placing FCER2 between D19S221 and D19S216. Furthermore, the disease locus should reside telomeric of the marker UT486. On the other hand, it is centromeric of D19S424 and D19S209 because the healthy child C3 is homozygous for D19S424 and other more telomeric markers due to a maternal crossing over. The healthy child C6 is heterozygous for D19S216 and D19S406 due to paternal crossing over and has the same allele constellation as his father. These results indicate that the disease locus may be located between UT486 and D19S424.

\section{DISCUSSION}

Starting with our working hypothesis that the aberrant TÜ1 reactivity has a molecular basis in the FCER2 gene, we de- 


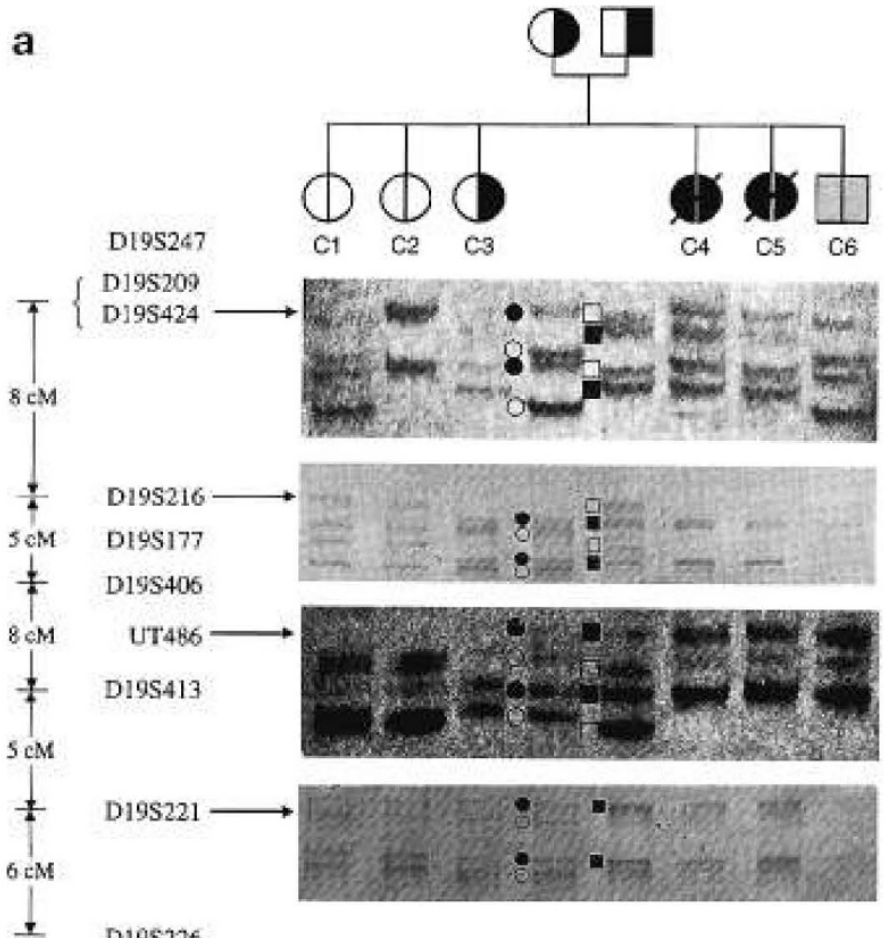

D195226

b

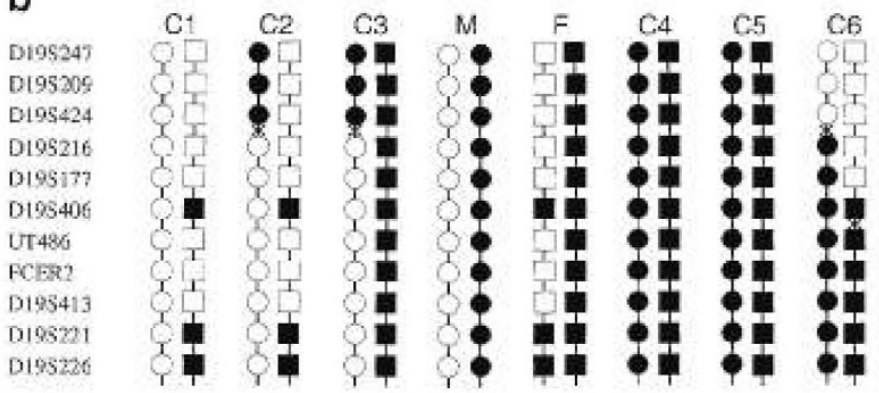

Figure 2. Segregation patterns of different chromosome 19p markers in the family studied. Filled symbols represent markers on the presumed disease haplotypes in the parents. The pedigree has been aligned to the lanes of the gels. (a) Microsatellite analysis of the chromosomal region 19p13.3. Markers [top to bottom: D19S424 (16), D19S216 (15), UT486 (18) D19S221 (15)] were amplified under conditions given in the respective references. Products were analyzed by native or denaturing polyacrylamide gel electrophoresis or by SSCP. (b) Haplotype constellations for chromosomal region 19p markers. Filled symbols represent alleles on the disease haplotype (which is shared by mother and father); open symbols represent other alleles. $\times$ represents a crossing over event. Crossing over in the paternal haplotype between D19S177 and D19S406 in child C6 is also compatible with the data.

tected a HpaII RFLP in this gene that cosegregates with the disease phenotype. However, the mutated $\mathrm{Fc}_{\epsilon}$ receptor itself cannot give rise to the disease because class II-deficient CID patients, unrelated to the members of our family, did not exhibit FCER2 mutations. Cells from a further affected child were also unreactive with TÜ1, comparable to family members $\mathrm{C} 4$ and C5, but these cells were not available for this study. An exception of this was represented by child C6. The DNA analyzed was obtained from chorionic villi samples of a pregnancy existing at the time of the investigation. Analysis of the HpaII RFLP indicated homozygosity for the FCER2 mutation so that it was initially assumed that the child would exhibit the disease. A determination of HLA class II antigen expression on cells in fetal blood and peripheral blood of the child C6, however, demonstrated a normal expression of these molecules (data not shown).

These findings can be explained by the analysis of several highly informative microsatellite markers, which show that a crossing over in $19 p$ in the mother and in the father occurred. Therefore, in the case of C6, D19S216, D19S406, and D19S177 did not show the allele constellation expected for a diseased individual, indicating that this region is well separated from FCER2. Although the family investigated is small, a positive LOD score just above 1 for linkage between the disease locus and the markers D19S216 and D19S177 is obtained.

The presented results might offer the possibility of an earlier prenatal diagnosis for a subgroup of patients with HLA class II-deficient CID. Previously, direct determination of HLA class II antigen expression was possible only at about wk 20 (22), but the characterization of two highly polymorphic DNA markers would allow the analysis of chorionic villi samples already in the 7th wk of pregnancy. However, it is clearly essential to investigate more families with this genetically heterogeneous inherited disorder to assess the true value of D19S177 and D19S216 in HLA class II-deficient CID.

Acknowledgment. The authors express their gratitude to all members of the affected family for their very close cooperation.

\section{REFERENCES}

1. Mach B, Steimle V, Reith W 1994 MHC class II-deficient combined immunodeficiency: a disease of gene regulation. Immunol Rev 138:207-221

2. Hadam MR, Dopfer R, Peter H-H, Niethammer D 1984 Congenital agammaglobulinemia associated with lack of expression of HLA-D-region antigens. In: Griscelli C, Vossen J (eds) Progress in Immunodeficiency Research and Therapy. Excerpta Medica, Amsterdam, pp 43-50

3. Griscelli C 1991 Combined immunodeficiency with defective expression in major histocompatibility complex class II genes. Clin Immunol Immunopathol 61:106110

4. de Préval C, Lisowska-Grospierre B, Loche M, Griscelli C, Mach B. 1985 A trans-acting class II regulatory gene unlinked to the MHC controls expression of HLA class II genes. Nature 318:291-293

5. Benoist C, Mathis D 1990 Regulation of major histocompatibility complex class-II genes: X, Y and other letters of the alphabet. Annu Rev Immunol 8:681-715

6. Glimcher LH, Kara CJ 1992 Sequences and factors: a guide to MHC class-II transcription. Annu Rev Immunol 10:13-49

7. Kara CJ, Glimcher LH 1993 Three in vivo promoter phenotypes in MHC class II deficient combined immunodeficiency. Immunogenetics 37:227-230

8. Kara CJ, Glimcher LH 1991 In vivo footprinting of MHC class II genes: bare promoters in the bare lymphocyte syndrome. Science 252:709-712

9. Steimle V, Otten LA, Zufferey M, Mach B 1993 Complementation cloning of an MHC class II transactivator mutated in hereditary MHC class II deficiency (or bare lymphocyte syndrome). Cell 75:135-146

10. Hadam MR, Heerwagen C, Ziegler A 1989 Aberrant expression of a CD23 epitope (TÜ1) on lymphoblastoid cell lines from two siblings with MHC class II deficiency. In: Knapp W, Dörken B, Gilks WR, Rieber EP, Schmidt RE, Stein H, van dem Borne AEGK (eds) Leucocyte Typing IV. Oxford University Press, Oxford, pp $74: 75$

11. Wendel-Hansen V, Rivière M, Uno M, Janson I, Szpirer J, Islam MQ, Levan G, Klein G, Yodoi J, Rosen A, Szpirer C 1990 The gene encoding CD23 leukocyte antigen (FceRII) is located on human chromosome 19. Somat Cell Mol Genet 16:283-286

12. Maniatis T, Fritsch EF, Sambrook J 1982 Molecular Cloning: A Laboratory Manual. Cold Spring Harbor Laboratory, Cold Spring Harbor, NY

13. Wanner R, Förster H.-H, Tilmans I, Mischke D 1993 Allelic variations of human keratins $\mathrm{K} 4$ and $\mathrm{K} 5$ provide polymorphic markers within the type II keratin gene cluster on chromosome 12. J Invest Dermatol 100:735-741

14. Weber JL 1992 Genome Data Base ID G00-036-129 (personal communication) 
15. Weissenbach J, Gyapay G, Dib C, Vignal A, Morisette J, Millasseau P, Vaysseix G, Lathrop M 1992 A second-generation linkage map of the human genome. Nature 359:794-801

16. Gyapay G, Morisette J, Vignal A, Dib C, Fizames C, Millasseau P, Marc S, Bernardi G, Lathrop M, Weissenbach J 1994 The 1993-94 Généthon human genetic linkage map. Nature Genet 7:246-339

17. Weber JL, May PE 1989 Abundant class of human DNA polymorphisms which can be typed using the polymerase chain reaction. Am J Hum Genet 44:388--396

18. Gerken SC, Matsunami N, Lawrence E, Carlson M, Moore M, Ballard L, Melis R, Robertson M, Bradley P, Elsner T, Tingey A, Rodriguez P, Albertsen H, Laouel J-M, White R 1993 GeneBank Accession No. L16263
19. Levitt RC, Jedlicka AE, Nouri N. 1992 Dinucleotide repeat polymorphism at the hormone sensitive lipase (LIPE) locus. Hum Mol Genet 1:139

20. Kikutani H, Inui S, Sato R, Barsumian EL, Owaki H, Yamasaki K, Kaisho T, Uchibayashi N, Hardy RR, Hirano T, Tsunasawa S, Sakiyama F, Suemura M Kishimoto T. 1986 Molecular structure of human lymphocyte receptor for immunoglobulin E. Cell 47:657-665

21. Suter E, Bastos R, Hofstetter H. 1987 Molecular structure of the gene and the $5^{\prime}$-flanking region of the human lymphocyte immunoglobulin $\mathrm{E}$ receptor. Nucleic Acids Res 15:7295-7308

22. Durandy A, Dumez Y, Guy-Grand E. 1982 Prenatal diagnosis of severe combined immunodeficiency. J Pediatr 101:995-997 